\title{
The Discovery of $[\mathrm{Ni}(\mathrm{NHC}) \mathrm{RCN}]_{2}$ Species and their Role as Cycloaddition Catalysts for the Formation of Pyridines
}

\author{
Ryan M. Stolley, Hung A. Duong, David R. Thomas, and Janis Louie * \\ Department of Chemistry, University of Utah, 315 South 1400 East, Salt Lake City, Utah \\ $84112-0850$
}

\begin{abstract}
The reaction of $\mathrm{Ni}(\mathrm{COD})_{2}, \mathrm{IPr}$, and nitrile affords dimeric $[\mathrm{Ni}(\mathrm{IPr}) \mathrm{RCN}]_{2}$ in high yields. X-ray analysis revealed these species display simultaneous $\eta^{1}$ - and $\eta^{2}$-nitrile binding modes. These dimers are catalytically competent in the formation of pyridines from the cycloaddition of diynes and nitriles. Kinetic analysis showed the reaction to be first order in $[\mathrm{Ni}(\mathrm{IPr}) \mathrm{RCN}]_{2}$, zeroth order in added IPr, zeroth order in nitrile, and zeroth order in diyne. Extensive stoichiometric competition studies were performed, and selective incorporation of the exogenous, not dimer bound, nitrile was observed. Post cycloaddition, the dimeric state was found to be largely preserved. Nitrile and ligand exchange experiments were performed and found to be inoperative in the catalytic cycle. These observations suggest a mechanism whereby the catalyst is activated by partial dimer-opening followed by binding of exogenous nitrile and subsequent oxidative heterocoupling.
\end{abstract}

\section{Keywords}

Nickel; Carbene; Cycloaddition; Nitrile; Catalysis; Mechanism; Bimetallic

\section{Introduction}

Due to the prevalence of pyridine-containing molecules in nearly all aspects of the chemical sciences, ${ }^{1}$ the ability to selectively synthesize structurally diverse pyridinecontaining molecules is paramount. Transition-metal catalyzed methods to prepare pyridine cores have become a significant synthetic route as they hold the potential to access highly functionalized pyridines in a simplistic and atom-economical fashion. ${ }^{2} \mathrm{~A}$ handful of transition metals have demonstrated the ability to co-cyclize alkynes and nitriles to make pyridines catalytically. Specifically, $\mathrm{Co},{ }^{3} \mathrm{Ru}^{4}{ }^{4}$ and $\mathrm{Rh}^{5}$ have received considerable attention. More recently, we and others have developed new $\mathrm{Ni}^{6}{ }^{6} \mathrm{Fe},{ }^{7}$ and $\mathrm{Ir}^{8}$ complexes that are able to catalyze pyridine formation.

Our discovery that a $\mathrm{Ni} / \mathrm{NHC}(\mathrm{NHC}=N$-heterocyclic carbene $)$ catalyst couples alkynes and nitriles to afford pyridines ${ }^{6 \mathrm{a}}$ is remarkable for a number of reasons: 1 ) $\mathrm{Ni}$ complexes readily catalyze the trimerization of alkynes (even in the presence of excess nitrile, eq 1$) ;{ }^{9}$ 2) $\mathrm{Ni}$ complexes readily undergo oxidative addition of R-CN bonds (eq 2); ${ }^{10} 3$ ) Ni complexes are known to cause homodimerization of nitriles; $;{ }^{9}$ and, perhaps most intriguingly, 4) $\mathrm{Ni}$

Corresponding Author: louie@chem.utah.edu.

Notes

The authors declare no competing financial interests.

Supporting Information. Full experimental details, spectral data, and X-ray data for 3a and 3c. This material is available free of charge via the Internet at http://pubs.acs.org. 
complexes catalyze a completely different reaction between alkynes and nitriles - namely, the carbocyanation of alkynes (eq 3). ${ }^{11}$ Despite these potential obstacles, the Ni/NHC catalyst efficiently converts a variety of nitriles and diynes into pyridines in generally high yields.
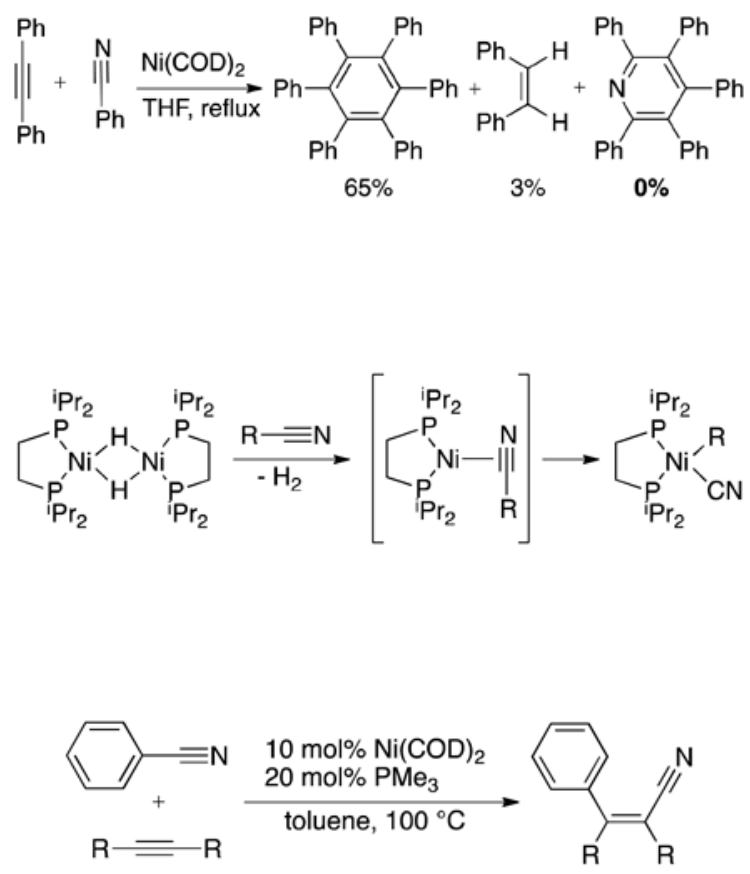

A cursory look into the possible mechanism of Nicatalyzed cycloaddition raises even more questions. Of the above-mentioned transition metals, the cobalt-catalyzed mechanistic pathway is the most thoroughly studied and is believed to proceed through a homocoupling pathway, i.e. Co undergoes oxidative homocoupling of the two alkynes before inserting the nitrile, with subsequent reductive elimination affording the desired product (Scheme 1). ${ }^{3,12}$ while considerably less studied, the reactions catalyzed by $\mathrm{Ru}$ and $\mathrm{Rh}$ are believed to undergo a similar homocoupling mechanism..$^{4 a-b, 5 a, 12}$ In contrast, Ni-mediated pyridine formation appears to follow a different route. Stoichiometric reactions of alkynes and azanickelacycles (prepared from transmetallation between an azazirconacyclopentenone and $\left.\mathrm{Ni}\left(\mathrm{PPh}_{3}\right)_{2} \mathrm{Cl}_{2}\right)^{13}$ afford highly-substituted pyridines suggesting that heterocoupling between a nitrile and an alkyne, rather than homocoupling of two alkynes, is the initial step (eq 4). Yet, the oxidative coupling of an alkyne and a nitrile is sluggish at best for $\mathrm{Ni}^{9}{ }^{9}$ and an isolable azanickelacycle has yet to be discovered (unlike other heteronickelacycles).

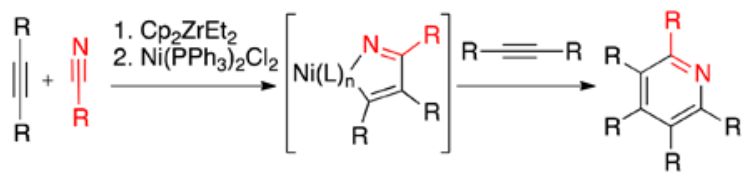


Further anecdotal evidence of an alternate oxidative heterocoupling pathway in the nickelcatalyzed system arises from the observed regioselectivity of the nickel-catalyzed cycloaddition of unsymmetrical diynes and nitriles (Scheme 2). ${ }^{6}$ If a homocoupling pathway were operative, the observed regiochemistry would dictate that insertion of the nitrile would require insertion from the sterically least-accessible face of intermediate $\mathbf{1}$. Alternatively, in order to minimize negative substrate/ligand steric interaction, heterocoupling of the bulkysubstituted alkyne with the nitrile would result in the observed regioselectivity (intermediate 2). This regioselectivity trend has also been observed in the Ni/NHC-catalyzed coupling of alkynes and aldehydes ${ }^{14}$ (as well as isocyanates ${ }^{15}$ ). Using DFT studies, Montgomery and Houk found that regioselectivity is primarily controlled by the steric hindrance at the region of the ligand closest to the alkyne. Analysis of steric contour maps of NHC ligands demonstrated that the regioselectivities are directly affected by the shape and orientation of the $N$-substituents on the ligand. ${ }^{16}$

Given the ambiguity surrounding the success of Ni-catalyzed pyridine formation, we initiated a mechanistic investigation of these cycloaddition reactions of alkynes and nitriles. We discovered an interesting nitrile-bound $\mathrm{Ni}(\mathrm{NHC})$ dimer resulting from the stoichiometric reaction between $\mathrm{Ni}(\mathrm{NHC})$ complexes and nitrile. Herein, we report the synthesis and characterization of these $\mathrm{Ni}$ dimers and their role in catalytic pyridine formation.

\section{Results}

\section{Synthesis of $[\mathrm{Ni}(\mathrm{IPr}) \mathrm{RCN}]_{2}$ Species}

The reaction of $\mathrm{Ni}(\mathrm{COD})_{2}, \mathrm{IPr}$, and acetonitrile (1:1:1 equiv) in $\mathrm{C}_{6} \mathrm{D}_{6}$ was observed in situ by ${ }^{1} \mathrm{H}$ NMR spectroscopy and revealed clean displacement of the COD ligands by IPr and nitrile to form a new complex ( $\operatorname{IPr}=1,3$-bis-(2,6-diisopropylphenyl)imidazol- 2-ylidene). Interestingly, relative intensities of ${ }^{1} \mathrm{H}$ resonances indicated a complex in which the ratio of IPr to acetonitrile was 1:1. A larger scale reaction between equivalent amounts of $\mathrm{Ni}(\mathrm{COD})_{2}, \mathrm{IPr}$ and acetonitrile in hexane or pentane at room temperature afforded 3a as a red precipitate in $76 \%$ yield (eq 5 ).

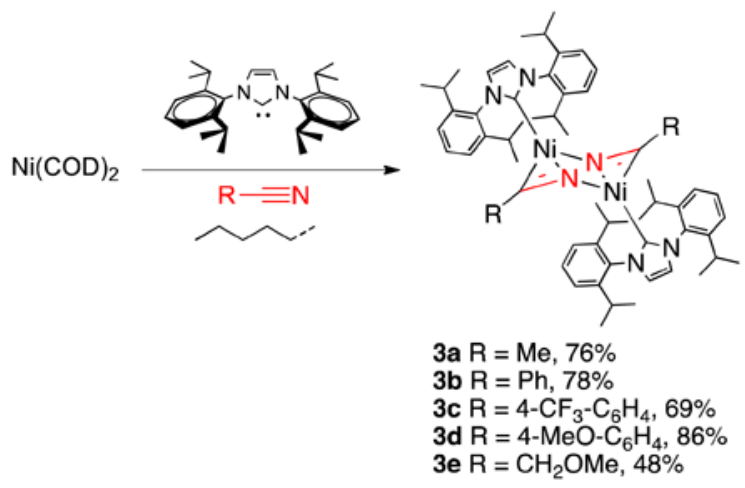

A single-crystal X-ray structure of 3a was obtained (Figure 1) wherein 3a was found to be an unexpected dimeric species in which one nitrile is bound to two Ni atoms in both $\eta^{1}$ - and $\eta^{2}$-binding modes. Importantly, an N-C bond length of 1.226(3) A was observed. This, along with a stretching frequency of $1757 \mathrm{~cm}^{-1}$, is indicative of an $\mathrm{N}-\mathrm{C}$ double bond of an $\eta^{2}$-bound nitrile. ${ }^{10,17}$ The Ni-N and Ni-C bond lengths are similar to those of analogous phosphine bound nickelnitrile complexes. ${ }^{17 \mathrm{~b}-\mathrm{c}}$ However, the Ni-C15 bond length of $\mathbf{3 a}$ is 
significantly shortened (1.8677 A vs. 2.1-2.2 $\AA$ ) compared to previously reported Ni-NHC bonds. ${ }^{18}$ Interestingly, the double hapticity of the nitriles has been observed with only select transition metals, ${ }^{17 \mathrm{a}}$ and to the best of our knowledge, has only been observed for nickel in tetranuclear species. ${ }^{17}$ Importantly, Signer analysis ${ }^{19}$ confirmed that 3a exists as a dimer in solution (MW = cald. 978.7; obsd 961.9 \pm 100 ) as well as the solid state. Dimers $\mathbf{3 b}-\mathbf{3 e}$ were prepared in a similar synthetic protocol from the requisite nitrile. The structure of $\mathbf{3 c}$ is shown in Figure 2. Not surprisingly, the Ni-C and N-C bond lengths are similar to those seen in 3a; only the Ni-N bond was slightly shorter (1.982 A vs. $1.995 \mathrm{~A})$. Attempts to form a dimer from isobutyronitrile and other bulky nitriles were unsuccessful and resulted in complex reaction mixtures.

\section{[Ni(IPr)RCN $]_{2}$-Catalyzed $[2+2+2]$ Cycloadditions}

When dimers 3 were employed as catalysts for the cycloaddition of diynes and nitriles, the expected pyridine products were obtained in good to excellent yields. Specifically, when diyne $\mathbf{4}$ and acetonitrile were subjected to $5 \mathrm{~mol} \%$ dimer $\mathbf{3 a}$, clean formation of pyridine $\mathbf{5 a}$ occurred (eq 6). Similarly, when aryl dimers $\mathbf{3 b}, \mathbf{3 c}$, and $\mathbf{3 d}$ were used as catalysts with $\mathrm{PhCN}$, 4- $\mathrm{CF}_{3} \mathrm{C}_{6} \mathrm{H}_{4} \mathrm{CN}$, and 4- $\mathrm{MeOC}_{6} \mathrm{H}_{4} \mathrm{CN}$, respectively, pyridines $\mathbf{5 b}-\mathbf{5 d}$ were obtained. Importantly, all yields compare favorably to those obtained in our parent $\mathrm{Ni}(\mathrm{COD})_{2} / \mathrm{SIPr}$ catalyst system $\left(\mathrm{SIPr}=1,3\right.$-bis-(2,6-diisopropylphenyl)-4,5-dihydroimidazol- 2-ylidene) ${ }^{6 \mathrm{a}}$

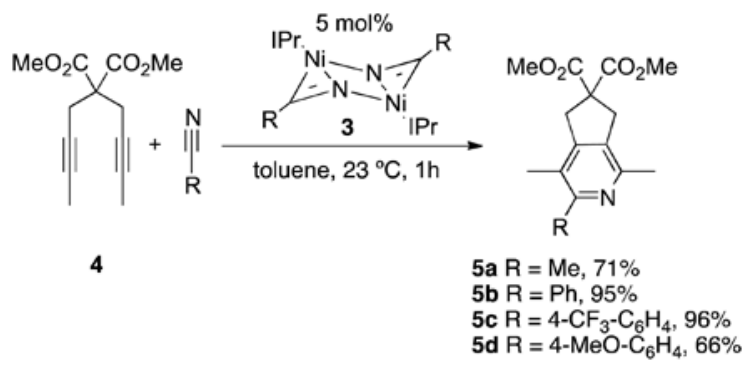

\section{Stoichiometric [2+2+2] Cycloadditions}

In contrast to the high yields observed in dimer catalyzed reactions, stoichiometric reactions between equimolar amounts of $\mathrm{Ni}$ dimers and diynes produced pyridines in unexpectedly low yields. However, when free nitrile was added, increased product yields were observed. For example, when 1 equivalent of diyne $\mathbf{4}$ was added to dimer $\mathbf{3 a}$, pyridine $\mathbf{5 a}$ was formed in $30 \%$ yield (eq 7, Table 1, entry 1). Yet, when diyne $\mathbf{4}$ (1 equiv) was added to dimer $\mathbf{3 a}$ in the presence of MeCN (1 equiv), pyridine $\mathbf{5 a}$ was formed in 64\% yield. The same phenomenon was observed in reactions with dimer $3 \mathbf{b}$ and $\mathrm{PhCN}$ (26\% vs. 91\% yield, entry 2), 3c and $4-\mathrm{CF}_{3} \mathrm{C}_{6} \mathrm{H}_{4} \mathrm{CN}$ (29\% vs. $63 \%$, entry 3), and $\mathbf{3 d}$ with $4-\mathrm{MeOC}_{6} \mathrm{H}_{4} \mathrm{CN}(34 \%$ vs $96 \%$ yield, entry 4$)$. Again, all yields obtained in the presence of free nitrile compare favorably to those obtained in our parent $\mathrm{Ni}(\mathrm{COD})_{2} / \mathrm{SIPr}$ catalyst system. ${ }^{6}$ 


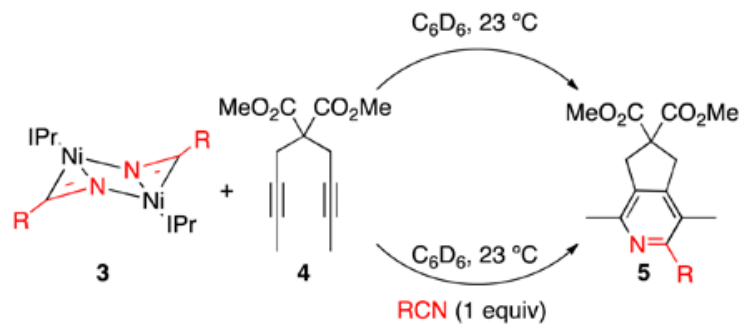

(7)

\section{Stoichiometric Cross-Cycloaddition Reactions}

The stoichiometric reaction of dimer $\mathbf{3 a}$, diyne $\mathbf{4}$, and $\mathrm{CD}_{3} \mathrm{CN}$ was also performed (eq 8). Surprisingly, the major pyridine product $\left(\mathbf{5 a}_{\boldsymbol{d}}\right)$ resulted from incorporation of $\mathrm{CD}_{3} \mathrm{CN}$, the exogenous nitrile, rather than the already bound acetonitrile.

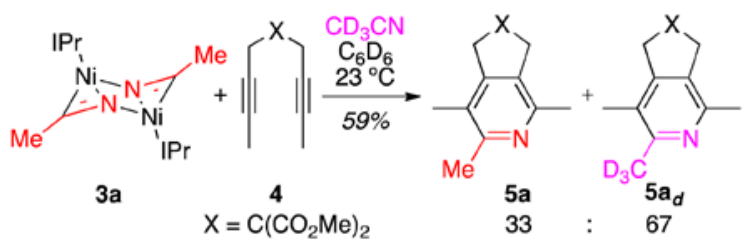

Other cross-cycloaddition combinations were evaluated to determine whether preferred incorporation of the exogenous nitrile was a general trend (eq 9). These results are summarized in Table 1. Upon examination, the exogenous, rather than the dimer-bound (i.e., endogenous or internal), nitrile was the most widely incorporated into the product. However, it is also worth noting that the dimer-bound nitrile was incorporated into a significant amount of product in some cases. Specifically, when dimer $\mathbf{3 b}$ reacted with exogenous $\mathrm{MeCN}$ and diyne $4,45 \%$ pyridine product $\mathbf{5 b}$, which incorporates the internal, Ni-bound benzonitrile, was formed (entry 2). Notably, when the exogenous $\mathrm{MeCN}$ was supplied in heavy excess (10 equiv), the ratio of products changed only slightly (entry 2 vs entry 3, 1:1.6 vs 1:2.9). Similar trends were observed in reactions with other aryl nitrile-bound dimers and exogenous $\mathrm{MeCN}$ (entries 6-7 and 9). Conversely, when exogenous $\mathrm{PhCN}$ reacted with diyne $\mathbf{4}$ and dimer 3a, PhCN was almost exclusively incorporated into the product (entry 1).

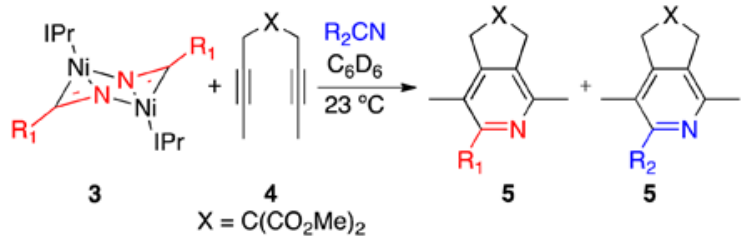

The stoichiometric cross-cycloaddition of diyne $\mathbf{4}$ and dimer $\mathbf{3 b}$, which is ligated with $\mathrm{PhCN}$, with electronically dissimilar $4-\mathrm{CF}_{3}-\mathrm{PhCN}$ and $4-\mathrm{MeO}-\mathrm{PhCN}$ were also carried out (entries 4 and 5). Surprisingly, the yields and product distributions were nearly identical. 
That is, in both cases, the exogenous nitrile is preferentially incorporated and afforded a mixture of pyridines in $\sim 95 \%$ yield and in a 1: 4 ratio (internal vs. exogenous nitrile incorporation). The high yields of pyridines $\mathbf{5 c - 5 d}$ obtained in these cross-cycloaddition reactions is in stark contrast to the individual catalytic and stoichiometric yields for these respective nitriles (eqs 9-10) where pyridine 5d was formed in lower yields (31-63\%). In almost every case where $\mathrm{MeCN}$ was used as the exogenous nitrile, overall pyridine yields were modest (compared to those employing only aryl nitriles) and agreed with the pyridine yield from $\mathrm{Ni}(\mathrm{COD})_{2} / \mathrm{SIPr}$-catalyzed cycloaddition of $\mathbf{4}$ and $\mathrm{MeCN}$. The one exception to this observation was when 10 equivalents of $\mathrm{MeCN}$ was used in the reaction with $\mathbf{4}$ and $\mathbf{3 c}$; a considerably higher yield was observed (91\%, entry 7 ). In addition to lower yields, lower selectivity for the exogenous nitrile was observed when $\mathrm{MeCN}$ was used as the exogenous nitrile.

Also summarized in Table 2, the identity of the dimer at the end of the reaction was predominately the dimer that was initially employed for the reaction. That is, when dimer 3a, diyne 4, and $\mathrm{PhCN}$ were reacted (to form predominately pyridine $\mathbf{5 b}$ ), only dimer $\mathbf{3 a}$ (not dimer $\mathbf{3 b}$ which possesses bound $\mathrm{PhCN}$ ) was observed after full consumption of both diyne and nitrile (entry 1). In the cases where $\mathrm{MeCN}$ was supplied in heavy excess (10 equiv), significant amounts of other $\mathrm{Ni}$ species were present as indicated by unknown resonances in the ${ }^{1} \mathrm{H}$ NMR spectrum (entries 3 and 7). Presumably, these resonances can be attributed to a mixed Ni dimer species (such as 3ab), although attempts to isolate these mixed species thus far have been unsuccessful.

\section{Kinetic Analysis of the $[\mathrm{Ni}(\mathrm{IPr}) \mathrm{MeCN}]_{2}-$ Catalyzed $[2+2+2]$ Cycloaddition of Diyne 4 and $\mathrm{MeCN}$}

Using the cycloaddition of diyne $\mathbf{4}$ and $\mathrm{MeCN}$ catalyzed by dimer $\mathbf{3 a}$ as a model, pseudofirst-order kinetic analyses were used to determine the substrate dependence of dimer, diyne, nitrile, and IPr. All kinetic evaluations were performed via ${ }^{1} \mathrm{H}$ NMR spectroscopy at $0^{\circ} \mathrm{C}$ in toluene- $d_{8}$ using either ferrocene or 1,3,5-trimethoxybenzene as an internal standard. Clean kinetics revealed the reaction to be first-order in $\mathbf{3 a}$ and zeroth-order in $\mathbf{4}, \mathrm{MeCN}$, and $\mathrm{IPr}$ (Figure 3).

\section{Dimer Crossover and Ligand Exchange Experiments}

When equimolar amounts of $\mathbf{3 a}$ and $\mathbf{3 b}$ were combined in a solution of benzene- $d_{6}$ at $\mathbf{r t}$, no detectable amount of mixed dimer (i.e. 3ab) ${ }^{13}$ was observed after one hour at room temperature (eq 10). ${ }^{14}$

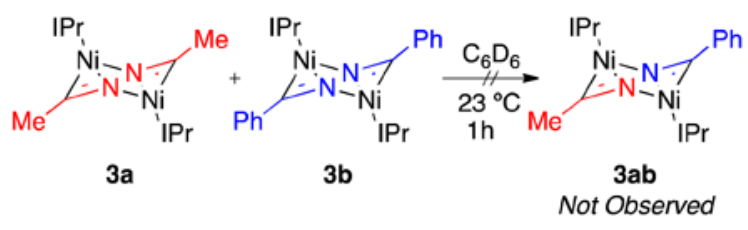

In contrast, a possible mixed-dimer species formed when a sterically- and electronicallyequivalent nitrile was added to dimer 3a (eq 11). That is, upon exposure of $\mathbf{3 a}$ to one equivalent of $\mathrm{CD}_{3} \mathrm{CN}, 50 \%$ consumption of $\mathbf{3 a}$ was observed in addition to the free, unligated $\mathrm{MeCN}$ after one hour at room temperature. The nature of the deuterated exchangeproduct (3ac or 3ad) is unknown. Similar nitrile exchange was observed when the more electrophilic benzonitrile was added to dimer $\mathbf{3 a}$ (eq 12). Within minutes, $\mathbf{3 b}, \mathbf{3 a}$, and free 
acetonitrile, along with resonances corresponding to an unknown species (presumably $\mathbf{3 a b}$ ), were observed by ${ }^{1} \mathrm{H}$ NMR spectroscopy in the reaction of $\mathbf{3 a}$ with free benzonitrile at room temperature. Complete exchange occurred in roughly an hour and a half. Conversely, a solution of $\mathbf{3 b}$ and acetonitrile exhibited no exchange under the same conditions and the same reaction timescale (eq 13), although a complex mixture was observed after 3 hours.
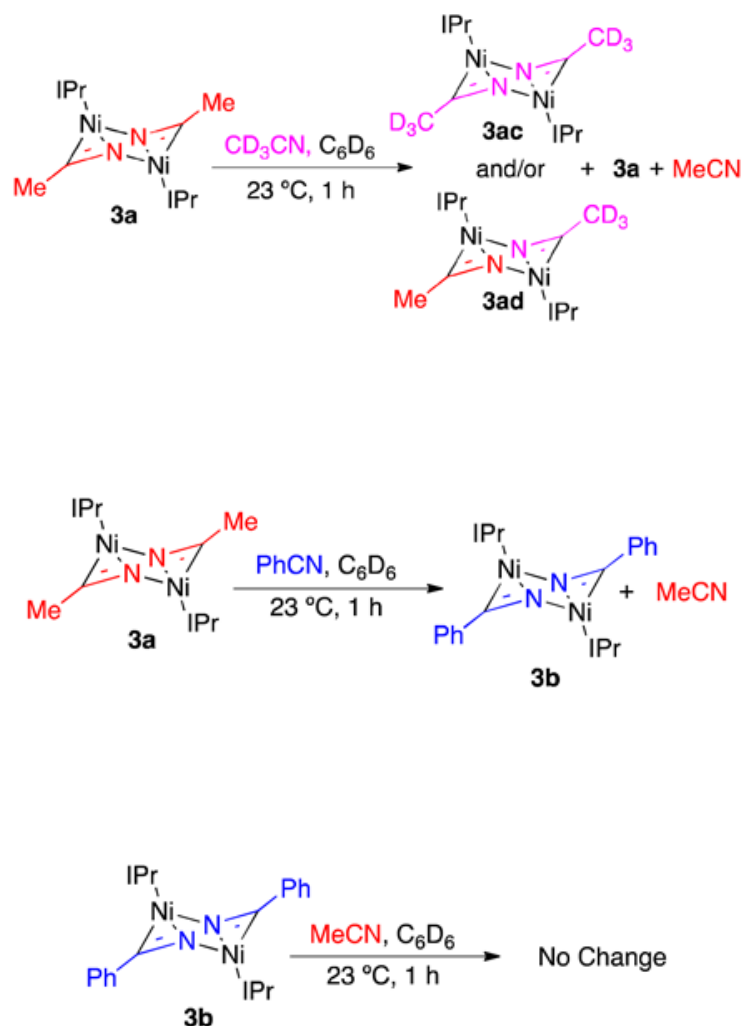

Unlike the nitrile exchange reactions, dimers $\mathbf{3 a}$ and $\mathbf{3 b}$ displayed analogous reactivity toward free IPr ligand. When either $\mathbf{3 a}$ or $\mathbf{3 b}$ were exposed to excess IPr- $d_{2}$ in $\mathrm{C}_{6} \mathrm{D}_{6}$ at room temperature, no ligand exchange was observed even after 3 hours. Similarly, no ligand exchange was observed in the reaction of dimer $\mathbf{3 a}$ or $\mathbf{3 b}$, excess IPr- $d_{2}$, and 1 equiv of free nitrile (acetonitrile or benzonitrile, respectively, eq 14). The stoichiometric reaction of $\mathbf{3 a}$, diyne 4, and MeCN was also carried out in the presence of IPr- $d_{2}$ (1-5 equivalents) Upon completion of the cycloaddition reaction no ligand exchange was observed (eq 15).

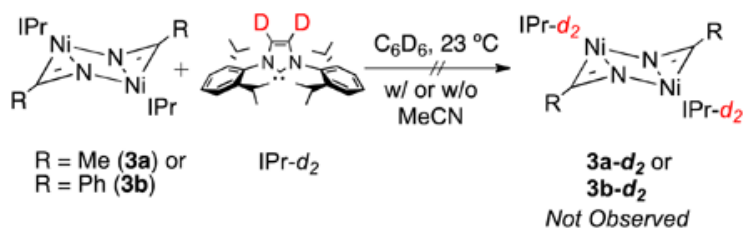




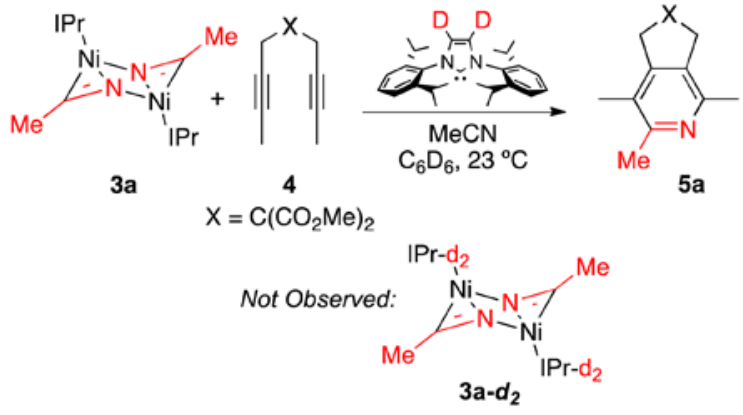

\section{Discussion}

At the onset of our research, four reasonable and relatively simplistic mechanisms were proposed (Scheme 3). The most straightforward pathway, A, begins with an initial dimer dissociation to an active monomeric form $\mathbf{3}_{\text {mon }}$. Following dissociation, we envision alkyne binding followed by subsequent oxidative coupling, alkyne insertion, and, finally, reductive elimination. Alternatively, in order to generate an open coordination site, IPr ligand could occur (pathway $\mathbf{B}$ or $\mathbf{C}$ ). Pathway $\mathbf{B}$ involves initial alkyne binding followed by partial dimer dissociation and oxidative coupling of the proximal nitrile thereby generating an open dimeric species $\mathbf{3}_{\mathbf{L L}}$. Nitrile and/or IPr-facilitated reductive elimination then regenerates the dimer. Pathway $\mathbf{C}$, on the other hand, involves initial nitrile binding subsequent to ligand loss. This externally bound nitrile (i.e., of an exogenous nitrile) then undergoes oxidative coupling and insertion on the "outside" of the dimer species $\left(\mathbf{3}_{\text {out }}\right)$. In an entirely different process, an alternative pathway (pathway $\mathbf{D}$ ) is initiated by an incomplete dissociation or dimer opening $\left(\mathbf{3}_{\text {open }}\right)$. Alkyne binding onto the open dimer followed by IPr loss then leads to oxidative coupling with an internally bound nitrile. Nitrile/IPr facilitated reductive elimination then regenerates the dimer.

\section{Systematic Evaluation of the Proposed Mechanistic Pathways}

\section{Pathway A}

Mechanistically, we initially surmised pathway $\mathbf{A}$ was the operative pathway as it is the most simplistic and straightforward. However, the kinetic evaluation of the cycloaddition of 4 and $\mathrm{MeCN}$ catalyzed by $\mathbf{3 a}$, revealed the rate of cycloaddition depended solely on the concentration of dimer (i.e., a first-order dependence of dimer 3a). This data reveals that the dimer must be on the catalytic pathway (otherwise autocatalytic behavior would be observed). Thus, in a modified pathway $\mathbf{A}^{\prime}$ (Scheme 4), the dimer is the catalyst resting state and dimer dissociation is rate limiting. The observed irreversibility may be attributed to the high activity of the monomer $\left(\mathbf{3}_{\mathbf{m o n}}\right)$. However, as seen in the stoichiometric reactions of dimers 3a-3d with diyne 4, added nitrile is required for optimal yield (Table 1, eq 7). If dissociation were operative, one would expect complete consumption of dimer and high pyridine yields without the need for additional nitrile. In addition, each of these stoichiometric cycloaddition reactions (without added nitrile, eq 7) afforded pyridines in comparable yields despite considerable differences in their reactivity (i.e., $\mathbf{3} \mathbf{a}<\mathbf{3 b}$ ) suggesting that catalyst degradation products that may facilitate homodimerization of diyne 4 (at a faster rate than cycloaddition) ${ }^{20}$ does not account for the added nitrile requirement. Furthermore, if dimer to monomer dissociation were operative, dimer crossover would be expected, yet no cross over is observed even in trace amounts (eq 10). 
An alternative possibility that still includes dimer-tomonomer dissociation involves generation of a small amount of catalytically active monomer from catalytically inactive dimer (Pathway $\mathbf{A}^{\prime \prime}$, Scheme 5). At first glance, assuming dimer degradation to monomer $\mathbf{3}_{\mathbf{m o n}}$ was first order and much slower than cycloaddition, such a mechanism would account for 1) the lack of dimer crossover observed (eq 10), 2) the observed dimer species at the end of the cycloaddition reaction (i.e., the original dimer is almost always observed) and 3) the selective incorporation of the exogenous nitrile. However, several stoichiometric crosscycloaddition reactions rule out this possibility. For example, the reaction of dimer $\mathbf{3 b}$, diyne $\mathbf{4}$, and $\mathrm{MeCN}$ affords the phenyl-substituted pyridine $\mathbf{5 b}$ in $28 \%$ yield (Table 2, entry 2). To accommodate this yield, at least $14 \%$ of the applied dimer $\mathbf{3 b}$ must dissociate to $\mathbf{3} \mathbf{b}_{\mathbf{m o n}}$ and react with diyne $\mathbf{4}$ to afford $\mathbf{5 b}$. Once pyridine $\mathbf{5 b}$ is formed, the only reactants left are $\mathrm{MeCN}$, and possibly free IPr. As such, dimer $3 \mathbf{a}$ or $\mathrm{Ni}(\operatorname{IPr})_{\mathrm{n}}$ would be formed in a detectable amount (i.e., 14\%). Yet, upon completion of the reaction, the only carbene species present is from 3b, not 3a; no other species were present. Generally, of the Ni-species present postreaction, nitrile exchange products that arise through diyne-free nitrile exchange were the only other observed products (eq 12-13).

The cross-cycloaddition of $\mathbf{3 b}$ with diyne $\mathbf{4}$ and both 4- $\mathrm{CF}_{3}-\mathrm{PhCN}$ and 4-MeO-PhCN (Table 2 , entries 4 and 5) provides more evidence against a negligible amount of dimer dissociation/degradation product as the active catalyst. Both of these cross-cycloaddition reactions afforded comparable pyridine yields and product ratios (i.e., similar amount of exogenous nitrile incorporation). However, catalytic cycloaddition of $4-\mathrm{CF}_{3}-\mathrm{PhCN}$ is higher yielding than 4-MeOPhCN (eq 6). As such, a small concentration of active $\mathbf{3} \mathbf{b}_{\mathbf{m o n}}$ catalyst would have produced higher amounts of $\mathbf{5 c}$ than $\mathbf{5 d}$, in agreement with the catalytic reactions, rather than the similar yields observed. A similar phenomenon is observed in the discrepancy between the observed effects of increasing the equivalents of applied nitrile. In the cycloaddition of $\mathbf{3 b}, \mathbf{4}$, and 10 equivalents of $\mathrm{MeCN}$ (Table 2, entry 3) a mild decrease in yield and a two-fold increase in selectivity for $\mathrm{MeCN}$ were observed. This is contrary to the cycloaddition of $\mathbf{3 c}, \mathbf{4}$, and 10 equivalents of $\mathrm{MeCN}$ (Table 2, entry 7) where a significant increase in yield and only mild increase in selectivity were observed.

Lastly, if a negligible amount of dimer $\mathbf{3}$ degrades into an active catalyst (e.g., not necessarily $\mathbf{3}_{\mathbf{m o n}}$ ), the incorporation of exogenous nitrile would be directly related to the stability of the dimer. That is, faster dimer degradation would result in more exogenous nitrile incorporation. Thus, product ratios would suggest a dimer stability trend of $\mathbf{3 a}<\mathbf{3 d}<$ $\mathbf{3 b} \approx \mathbf{3} \mathbf{c}$ where $3 \mathbf{a}$ is the least stable since it incorporates the most exogenous nitrile (Table 2). However, qualitative measurement of the decomposition of the dimers displayed the opposite relative stabilities $(\mathbf{3 a} \gg \mathbf{3 d}>\mathbf{3 b} \approx \mathbf{3} \mathbf{c})$ where $\mathbf{3 a}$ was the most stable to decomposition.

Taken together, our data suggest the dissociative pathway $\mathbf{A}$ (or $\mathbf{A}^{\prime}$ ) is not operative.

\section{Pathways B and C}

Just as with pathway $\mathbf{A}$, pathways $\mathbf{B}$ and $\mathbf{C}$ are also straightforward to envision. With exclusive firstorder dependence in dimer for the cycloaddition reaction, IPr loss must be rate-determining if either pathway (B or $\mathbf{C})$ were operative. However, when both $\mathbf{3 a}$ and $\mathbf{3 b}$ were individually treated with $\operatorname{IPr}-d_{2}$ (eq 14), no ligand exchange was observed.

Additionally, no ligand exchange occurred when either $\mathbf{3 a}$ or $\mathbf{3 b}$ were treated with IPr- $d_{2}$ in the presence of the requisite nitrile. Furthermore, no ligand exchange occurred when $\mathbf{3 a}$ or $\mathbf{3 b}$ were used in the cycloaddition of diyne $\mathbf{4}$ and nitrile in the presence of excess IPr- $d_{2}$ (eq 15). As such, the lack of observable ligand exchange in conjunction with our kinetic data rule out pathways $\mathbf{B}$ and $\mathbf{C}$. 


\section{Pathway D}

Given the congested nature of dimers $\mathbf{3}$, ratelimiting partial dimer opening would allow for subsequent substrate binding and reaction and would agree with our kinetic data. Subsequent to rate-determining dimer opening, a mechanism involving oxidative coupling and insertion of the diyne followed by nitrile-assisted reductive elimination agrees with not only with our kinetic data but our stoichiometric analyses which showed the requirement of added nitrile for high pyridine yield (eq 6). Nevertheless, our stoichiometric cross-cycloaddition reactions rule out pathway $\mathbf{D}$ since this pathway would provide pyridine products that incorporate the internally-bound nitrile, rather than the exogenous nitrile. For example, in the reaction of $\mathrm{MeCN}$-bound dimer 3a, diyne 4, and $\mathrm{PhCN}$, pyridine $\mathbf{5 b}$ (which incorporates exogenous $\mathrm{PhCN}$ ) is formed almost exclusively. However, in the reaction of $\mathrm{PhCN}$-bound dimer $\mathbf{3 b}$, diyne $\mathbf{4}$, and $\mathrm{MeCN}$, pyridines $\mathbf{5 a}$ (which incorporates exogenous $\mathrm{MeCN}$ ) and $\mathbf{5 b}$ are formed in almost equally with a moderate preference for $\mathbf{5 b}$ (1:1.6, Table 2, entry 2$)$. Furthermore, to account for these product distributions, the reactivity of a mixed dimer intermediate (3ab) would react one way in the first reaction $\left(\mathbf{3 a b}_{\mathbf{P h}}\right)$ but in the opposite way in the latter reaction ( $\mathbf{3 a b}_{\mathbf{M e}}$, Scheme 6).

Alternatively, if we were to explain the exclusive formation of $\mathbf{5 b}$ through nitrile exchange, another contradiction would occur. That is, initial nitrile exchange of $\mathbf{3 a}$ and $\mathrm{PhCN}$ would result in the formation of $\mathbf{3 b}$ and $\mathrm{MeCN}$. Yet, reaction of $\mathbf{3 b}$ and $\mathrm{MeCN}$ (and diyne) afforded a mixture of products rather than almost exclusive formation of $\mathbf{5 b}$ (Table 2, entry 1). Our other cross-cycloaddition reactions further highlight this discrepancy. If incorporation of the exogenous nitrile were explained solely through nitrile exchange, a higher incorporation of 4- $\mathrm{CF}_{3}-\mathrm{PhCN}$ relative to $4-\mathrm{MeO}-\mathrm{PhCN}$ (since $4-\mathrm{CF}_{3}-\mathrm{PhCN}$ exchanges more readily than 4$\mathrm{MeO}-\mathrm{PhCN}$ ) would be expected. Instead, equal ratios of pyridine products are observed when $3 \mathbf{b}$, diyne 4 , and either $4-\mathrm{CF}_{3}-\mathrm{PhCN}$ or $4-\mathrm{MeO}-\mathrm{PhCN}$ are reacted (Table 1 , entries 4 and 5). As such, the last of the initial mechanisms, pathway $\mathrm{D}$, can be ruled out.

\section{Pathway E}

Although delineating a detailed mechanism of a reaction with an early rate-determining step is difficult, our data suggest a mechanism that does indeed involve partial dimer opening. However, rather than subsequent reaction with alkyne, nitrile binding immediately follows dimer opening since, regardless of electronic bias, the exogenous nitrile is selectively incorporated. Our kinetic data and all of our stoichiometric reactions suggests a nitrile cycloaddition mechanism past dimer opening that involves the following:

\section{Both of the initially-bound, endogenous nitriles must remain coordinated to the active catalyst throughout the entire reaction-Upon dimer opening, two} unique Nicoordination environments are formed (eq 16). One is a twocoordinate $\left(\mathrm{Ni}^{2}\right)$ and the other three-coordinate $\left(\mathrm{Ni}^{3}\right)$. Coordination of the external nitrile to $\mathrm{Ni}_{3 \mathrm{c}}$ would occur in an $\eta^{1}$-fashion, owing to the congested steric-environment. As such, a hapticity-shift would need to occur in the exogenous nitrile in order for subsequent oxidative heterocoupling. This is problematic in that selectivity for the exogenous nitrile would then be lost; and product distributions would be dictated by relative reactivities of the different nitriles, which is inconsistent with the observed product ratios. 


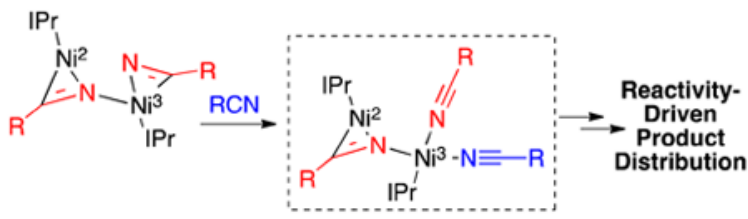

Alternatively, coordination of exogenous nitrile would occur at the less saturated $\mathrm{Ni}^{2}$ (eq 17). In this case, the internal (i.e., pre-coordinated) nitrile is in a unique $\eta^{2}, 1_{1}-\mu$-binding motif, which renders it inaccessible and/or unreactive. Thus, the exogenous nitrile remains in a coordination environment distinct from the internal nitrile. At this point, alkyne binding leads to subsequent cycloaddition with the only reactive nitrile available, namely the exogenous nitrile, thereby resulting in the observed product distribution.

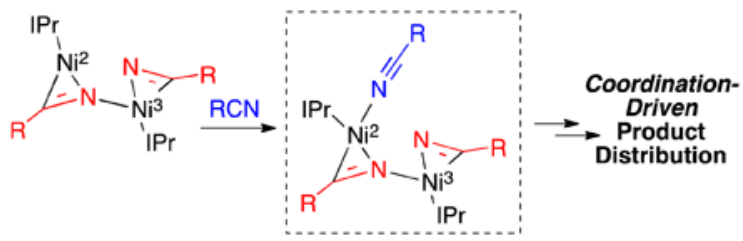

2. The catalyst maintains a bimetallic (or higher) motif-In order to accommodate the required continuous coordination of both initially-bound, endogenous nitriles, a bimetallic complex is necessary. As previously mentioned, if the dissimilar nitriles ever occupy an equivalent coordination environment, either simultaneously or step-wise, the reactivity would be dictated by the relative reactivities of the nitriles themselves. In this context, if the catalyst split into a monomeric form, all nitrile coordination-modes, and subsequent product distribution, would be dependent on the individual nitrile reactivities. Only through secondary coordination (aside from direct reaction) could nitrile resolution occur, in this case by effectively tying-up the internal nitrile.

3. There may be competing pathways-Binding of an exogenous nitrile appears to follow dimer opening followed by cycloaddition. To account for the consistent incorporation of the internal nitrile however, a competing pathway(s) must also be operative. Most likely, this arises through minimal nitrile exchange to facilitate the required coordination chemistry for cycloaddition.

Taken together, a mechanism (Pathway E) that includes these requirements is summarized in Scheme 7.

In summary, a new class of $\mathrm{Ni} /$ nitrile/NHC dimers have been isolated and characterized in an investigation of the unique reactivity of $\mathrm{Ni} / \mathrm{NHC}$ systems with nitriles. These dimers were found to be catalytically competent in the $[2+2+2]$-cycloaddition of nitriles and diynes to form pyridines. While initial hypotheses focused on a dimer-to-monomer dissociative pathway, a first-order dependence solely on dimer, lack of dimer-crossover, and poor stoichiometric yields in the absence of free nitrile instead suggest a cycloaddition mechanism involving partial dimer opening as the ratedetermining step. Immediate binding of an exogenous nitrile and subsequent reaction with diyne led to pyridine product as 
deduced from product ratios from competition reactions, ligand exchange reactions, and final outcome of the nickel species post-cycloaddition. Future work on this system will be focused on computational experiments, which may aid in determining the coordination environment of the $\mathrm{Ni}$ intermediates that form after the rate-limiting step. In addition, recent success in in situ mass spectrometric methods may also help elucidate the structure of some complex intermediates. ${ }^{21}$

\section{Supplementary Material}

Refer to Web version on PubMed Central for supplementary material.

\section{Acknowledgments}

We thank the NIH (GM076125) and NSF (0911017) for financial support of this work. We thank Drs. J. Muller and A. Arif for providing HRMS and X-ray spectroscopic data, respectively.

\section{References}

1. For leading sources see: Jones G. Katritzky A, Rees CW, Scriven EFV. Pyridines and their benzoderivatives: synthesis. Comprehensive Heterocyclic Chemistry II. PergamonOxford1996; 5:167.Alford PE. Gribble GW, Joule JA. Six-Membered Ring Systems: Pyridines and Their Benzo Derivatives. Progress in Heterocyclic Chemistry. ElsevierOxford2011; 22:349.Gonzalez-Bello C, Castedo L. Alvarez-Builla J, Vaquero JJ, Barluenga J. Six-membered Heterocycles: Pyridines. In. Modern Heterocyclic Chemistry. Wiley-VHCWeinheim2011; 3:1431.

2. (a) Varela JA, Saa C. Synlett. 2008; 17:2571.(b) Heller B, Hapke M. Chem Soc Rev. 2007; 36:1085. [PubMed: 17576476] (c) Henry GD. Tetrahedron. 2004; 60:6043.(d) Varela JA, Saa C. Chem Rev. 2003; 103:3787. [PubMed: 12964884]

3. (a) Weng CM, Hong FE. Organometallics. 2011; 30:3740.(b) Dahy AA, Koga N. J Organomet Chem. 2010; 695:2240.(c) Kase K, Goswami A, Ohtaki K, Tanabe E, Saino N, Okamoto S. Org Lett. 2007; 9:931. [PubMed: 17261007] (d) Wakatsuki Y, Yamazaki H. J Chem Soc Chem Comm. 1973; 8:280.(e) Wakatsuki Y, Yamazaki H. J Chem Soc Dalton. 1978; 10:1278.(f) Bonnemann H, Brinkmann R, Schenkluhn H. Synthesis. 1974; 8:575.(g) Naiman A, Vollhardt KPC. Angew Chem. 1977; 89:758.

4. (a) Yamamoto Y, Kinpara K, Ogawa R, Nishiyama H, Itoh K. Chem Eur J. 2006; 12:5618. [PubMed: 16755621] (b) Yamamoto Y, Kinpara K, Saigoku T, Takagishi H, Okuda S, Nishiyama H, Itoh K. J Am Chem Soc. 2005; 127:605. [PubMed: 15643884] (c) Yamamoto Y, Kinpara K, Nishiyama H, Itoh K. Adv Synth Catal. 2005; 347:1913.(d) Yamamoto Y, Ogawa R, Itoh K. J Am Chem Soc. 2001; 123:6189. [PubMed: 11414858] (e) Yamamoto Y, Okuda S, Itoh K. Chem Commun. 2001:1102.(f) Varela JA, Castedo L, Saa C. J Org Chem. 2003; 68:8595. [PubMed: 14575491]

5. (a) Diversi P, Ermini L, Ingrosso C, Lucherini A. J Organomet Chem. 1993; 447:291.(b) Tanaka K, Suzuki N, Nishida G. Eur J Org Chem. 2006:3917.(c) Tanaka K, Hara H, Nishida G, Hirano M. Org Lett. 2007; 9:1907. [PubMed: 17432866] (d) Wada A, Noguchi K, Hirano M, Tanaka K. Org Lett. 2007; 9:1295. [PubMed: 17343391]

6. (a) McCormick MM, Duong HA, Zuo G, Louie J. J Am Chem Soc. 2005; 127:5030. [PubMed: 15810832] (b) Tekavec TN, Zuo G, Simon K, Louie J. J Org Chem. 2006; 71:5834. [PubMed: 16839179] (c) Stolley RM, Maczka MT, Louie J. Eur J Org Chem. 2011:3815.(d) Kumar P, Prescher S, Louie J. Angew Chem Int Ed. 2011; 50:10694.

7. (a) D’Souza BR, Lane TK, Louie J. Org Lett. 2011; 13:2936. [PubMed: 21557582] (b) Wang CX, Li XC, Wu F, Wan BS. Angew Chem Int Ed. 2011; 50:7162.(c) Knoch F, Kremer F, Schmidt U, Zenneck U. Organometallics. 1996; 15:2713.

8. (a) Weding N, Jackstell R, Jiao H, Spannenberg A, Hapke M. Adv Synth Catal. 2011; 353:3423.(b) Onodera G, Shimizu Y, Kimura JN, Kobayashi J, Ebihara Y, Kondo K, Sakata K, Takeyuchi R. J Am Chem Soc. 2012; 134:10515. [PubMed: 22594561]

9. Eisch JJ, Ma X, Han KI, Gitua JN, Kruger C. Eur J Inorg Chem. 2001; 1:77. 
10. (a) Garcia JJ, Jones WD. Organometallics. 2000; 19:5544.(b) Garcia JJ, Brunkan NM, Jones WD. J Am Chem Soc. 2002; 124:9547. [PubMed: 12167049] (c) Garcia JJ, Arevalo A, Brunkan NM, Jones WD. Organometallics. 2004; 23:3997-4002.(d) Atesin TA, Li T, Lachaize S, Garcia JJ, Jones WD. Organometallics. 2008; 27:3811.(e) Schaub T, Doring C, Radius U. Dalton Trans. 2007; 20:1993. [PubMed: 17502932] (f) Wilting J, Muller C, Hewat AC, Ellis DD, Tooke DM, Spek AL, Vogt D. Organometallics. 2005; 24:13-15.

11. (a) Nakao Y, Oda S, Hiyama T. J Am Chem Soc. 2004; 126:13904-13095. [PubMed: 15506734] (b) Nakao Y, Yada A, Ebata S, Hiyama T. J Am Chem Soc. 2007; 129:2428-2429. [PubMed: 17295484] (c) Nakao Y, Yukawa T, Hirata Y, Oda S, Satoh J, Hiyama T. J Am Chem Soc. 2006; 128:7116-7117. [PubMed: 16734437]

12. Dazinger G, Torres-Rodrigues M, Kirchner K, Calhorda MJ, Costa PJ. J Organomet Chem. 2006; 691:4434.

13. (a) Takahashi T, Tsai FY, Kotora M. J Am Chem Soc. 2000; 122:4994.(b) Takahashi T, Tsai FY, Li Y, Wang H, Kondo Y, Yamanaka M, Nakajima K, Kotora M. J Am Chem Soc. 2002; 124:5059. [PubMed: 11982370]

14. (a) Tekavac TN, Louie J. Org Lett. 2005; 7:4037. [PubMed: 16119961] (b) Tekavac TN, Louie J. J Org Chem. 2008; 73:2641. [PubMed: 18318544]

15. Duong HA, Cross MJ, Louie J. J Am Chem Soc. 2004; 126:11438. [PubMed: 15366880]

16. Liu P, Montgomery J, Houk KN. J Am Chem Soc. 2011; 133:6956. [PubMed: 21506540] For related DFT studies of $\mathrm{Ni}(0) / \mathrm{Phosphine} \mathrm{systems} \mathrm{see:} \mathrm{Liu} \mathrm{P,} \mathrm{McCarren} \mathrm{PR,} \mathrm{Cheong} \mathrm{PHY,} \mathrm{Jamison}$ TF, Houk KN. J Am Chem Soc. 2010; 132:2050. [PubMed: 20095609] McCarren PR, Liu P, Cheong PHY, Jamison TF, Houk KN. J Am Chem Soc. 2009; 131:6654. [PubMed: 19397371]

17. (a) Michelin RA, Mozzon M, Bertani R. Coord Chem Rev. 1996; 147:299.(b) Bassi IW, Benedicenti C, Calcaterra M, Intrito R, Rucci G, Santini C. J Organomet Chem. 1978; 144:225.(c) Walther D, Schonberg H, Dinjus E. J Organomet Chem. 1987; 334:377.

18. (a) Matsubara K, Miyazaki S, Koga Y, Nibu Y, Hasimura T, Matsumoto T. Organometallics. 2008; 27:6020.(b) Danopoulos AA, Pugh D. Dalton Trans. 2008:30. [PubMed: 18399222]

19. (a) Signer R. Liebigs Ann Chem. 1930; 478:246.(b) Zoellner RW. J Chem Educ. 1990; 67:714.

20. Homodimerization of diyne $\mathbf{4}$ was observed in the crude reaction mixture.

21. Takats ZW, Wiseman JM, Gologan B, Cooks RG. Science. 2004; 306:471. [PubMed: 15486296] Perry RH, Splendore M, Chien A, Davis NK, Zare RN. Angew Chem Int Ed. 2011; 50:250.Johansson JR, Norden B. Proc Natl Acad Sci USA. 2012; 109:2186. [PubMed: 22331872]

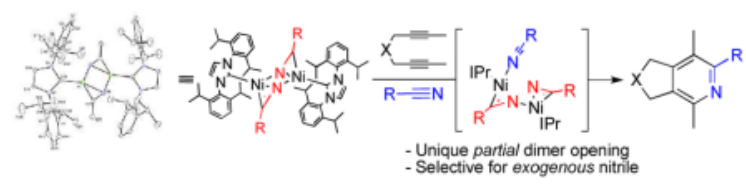

$J$ Am Chem Soc. Author manuscript; available in PMC 2013 September 12. 


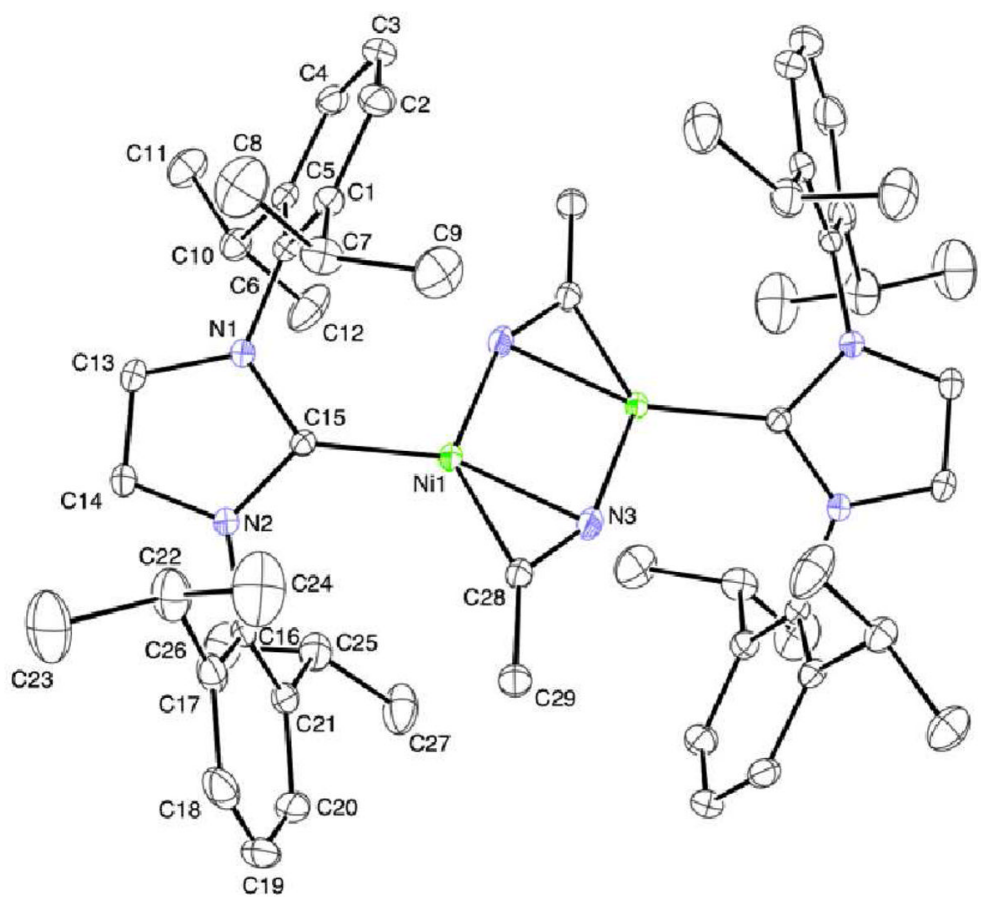

Figure 1.

Ortep plot of 3a at the $30 \%$ probability level. Hydrogen atoms omitted for clarity. Pertinent bond lengths include: $\mathrm{Ni}(1)-\mathrm{C}(28): 1.854 \AA$, Ni(1)-C(15): $1.8677 \AA$, Ni(1)-N(3): $1.9523 \AA$, $\mathrm{Ni}(1)-\mathrm{N}(3) \_3: 1.9951, \mathrm{~N}(3)-\mathrm{C}(28)$ : 1.226 . Pertinant bond angles include: $\mathrm{C}(28)-\mathrm{Ni}(1)-$ $\mathrm{C}(15): 120.29^{\circ}, \mathrm{C}(28)-\mathrm{Ni}(1)-\mathrm{N}(3): 37.37^{\circ}, \mathrm{C}(15)-\mathrm{Ni}(1)-\mathrm{N}(3) \_3: 132.83^{\circ}, \mathrm{N}(3)-\mathrm{Ni}(1)-\mathrm{N}(3) \_3$ : $95.37^{\circ}, \mathrm{N}(3)-\mathrm{C}(28)-\mathrm{C}(29): 134.6^{\circ}$. 


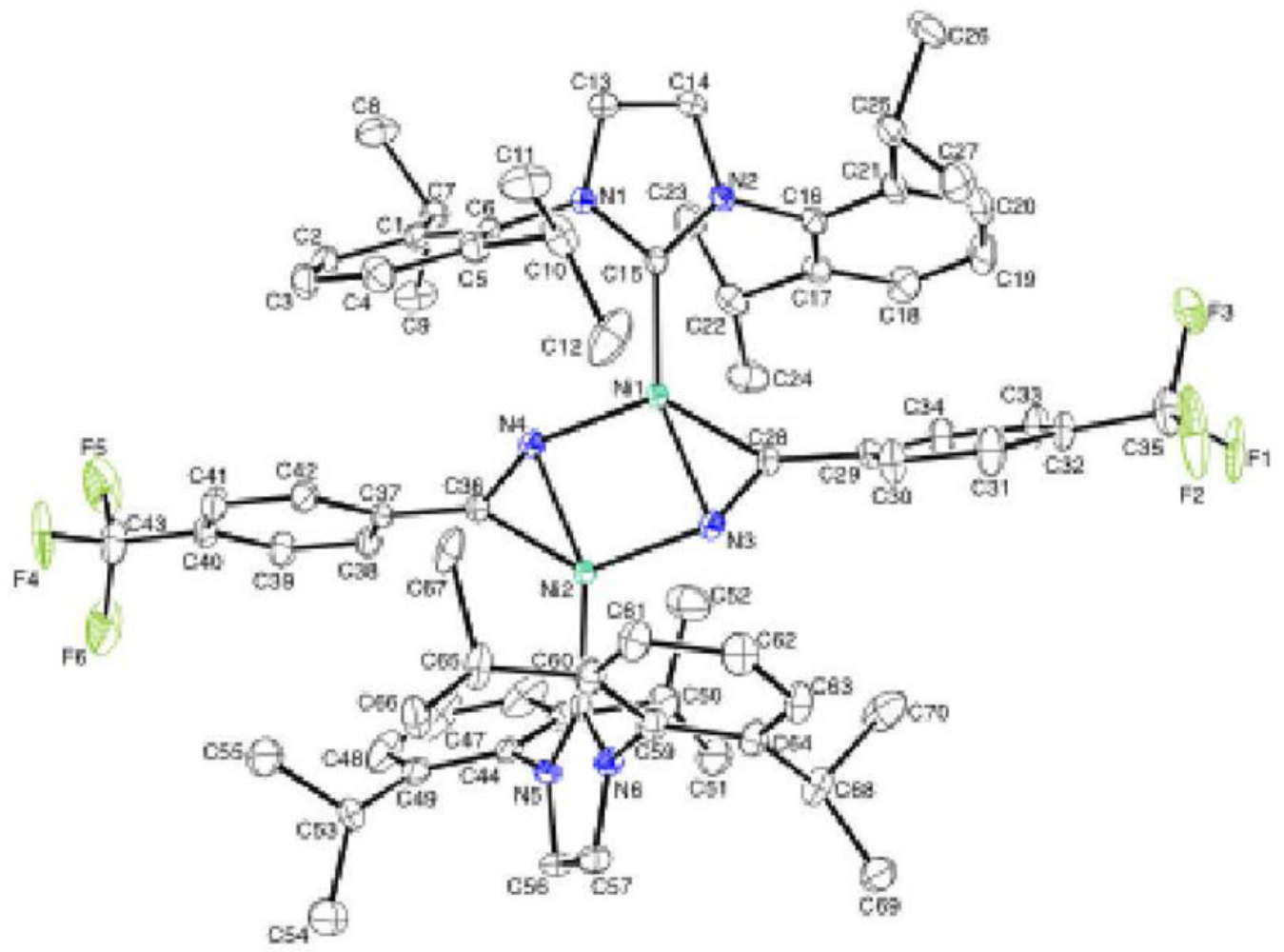

Figure 2.

Ortep plot of 3c. Hydrogen atoms are omitted for clarity. Pertinent bond lengths include: Ni(1)-C(28): $1.857 \AA$, Ni(1)-C(15): $1.895 \AA$ A, Ni(1)-N(3): $1.974 \AA$, Ni(1)-N(4): $1.982 \AA$, $\mathrm{N}(3)-\mathrm{C}(28): 1.223 \AA$ A. Pertinant bond angles include: $\mathrm{C}(28)-\mathrm{Ni}(1)-\mathrm{C}(15): 119.48^{\circ}, \mathrm{C}(28)-$ $\mathrm{Ni}(1)-\mathrm{N}(3): 37.08^{\circ}, \mathrm{C}(15)-\mathrm{Ni}(1)-\mathrm{N}(4): 109.50^{\circ}, \mathrm{N}(3)-\mathrm{Ni}(1)-\mathrm{N}(4): 93.93^{\circ}, \mathrm{N}(3)-\mathrm{C}(28)-$ $\mathrm{C}(29): 136.1^{\circ}$. 

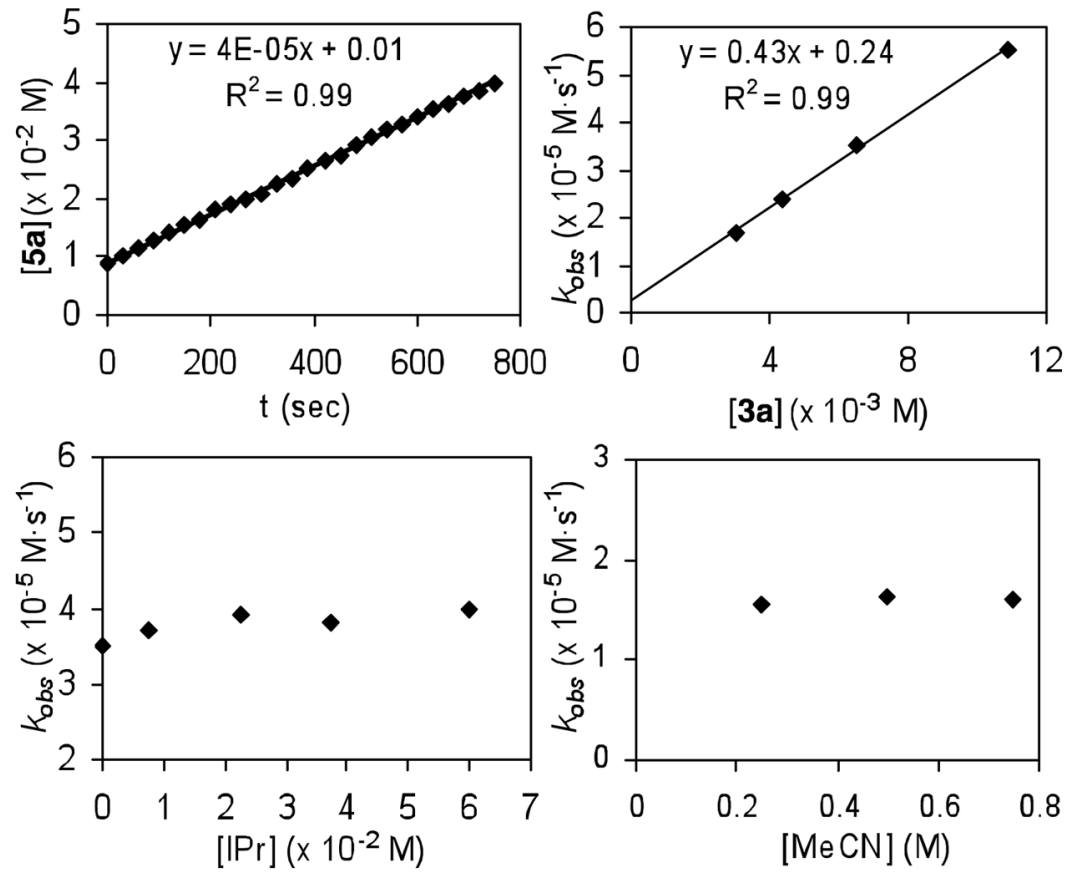

Figure 3.

Plots of [3a] vs. time, $k_{o b s}$ vs. [IPr], and $k_{o b s}$ vs- [MeCN] for the cycloaddition of $\mathbf{4}$ at $0{ }^{\circ} \mathrm{C}$ in $\mathrm{C}_{7} \mathrm{D}_{8}$ 


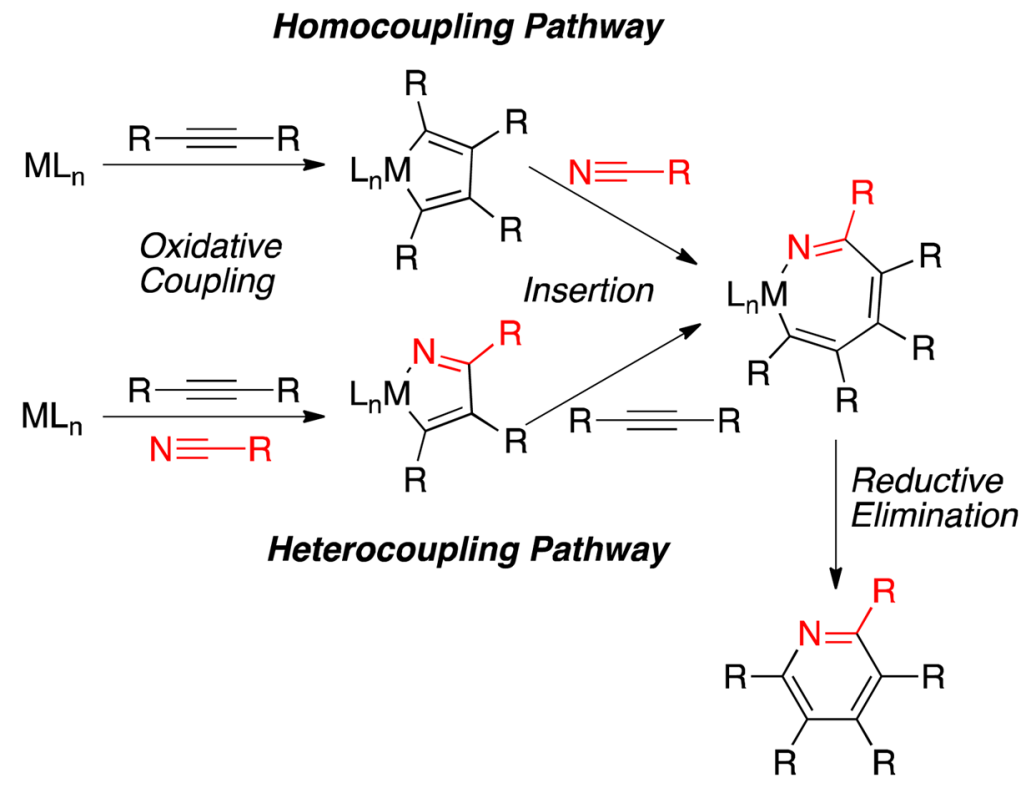

Scheme 1.

Divergent Pathways for Alkyne/Nitrile Cycloaddition 


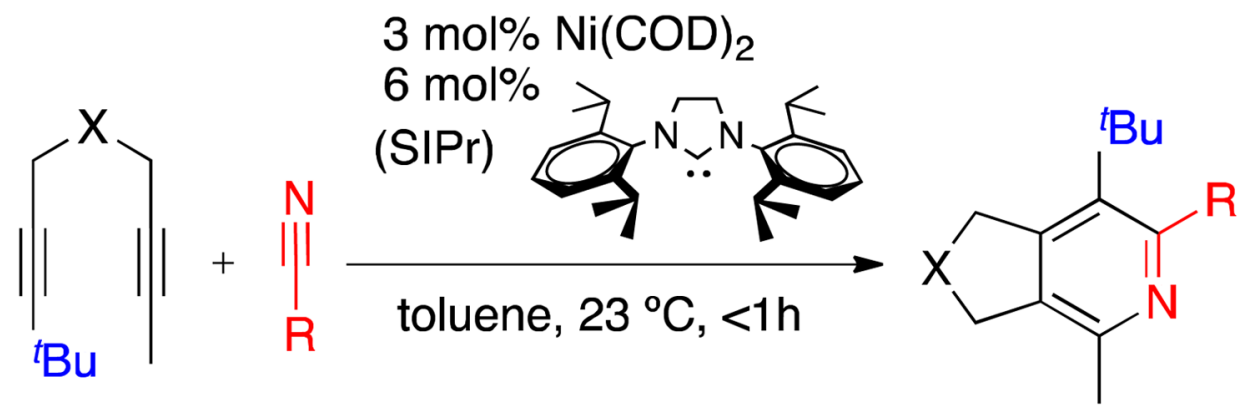

via: Homocoupling

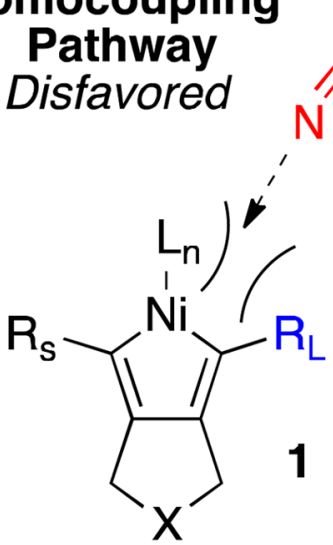

Heterocoupling

Pathway

Favored<smiles>[Y]CCC1=C([R])C([R])=N[N+]1(C)CC</smiles>

Scheme 2.

Observed regioselectivity in Ni/SIPr catalyzed cycloaddition 

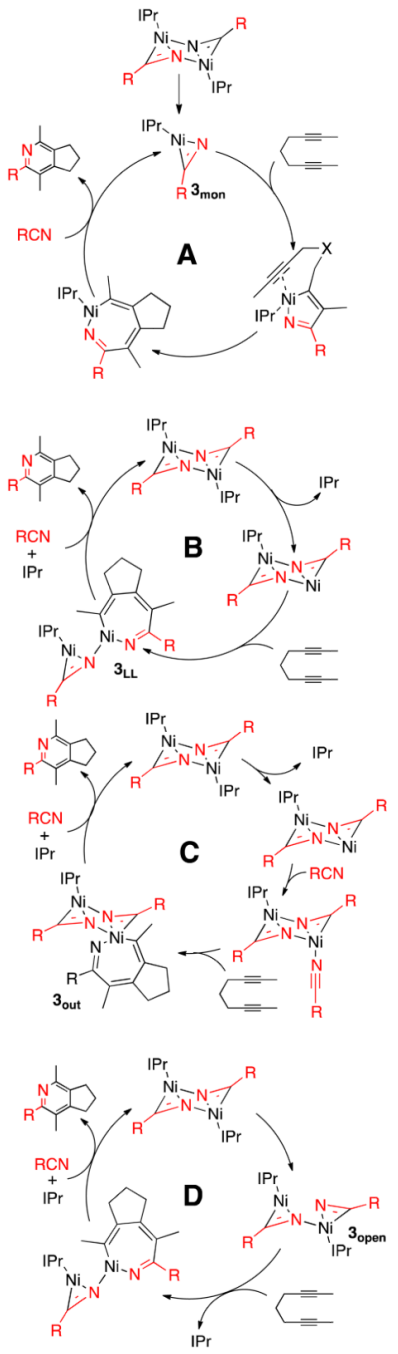

Scheme 3.

Possible Mechanistic Pathways for $[\mathrm{Ni}(\mathrm{IPr}) \mathrm{RCN}]_{2}$-Catalyzed Cycloadditions 


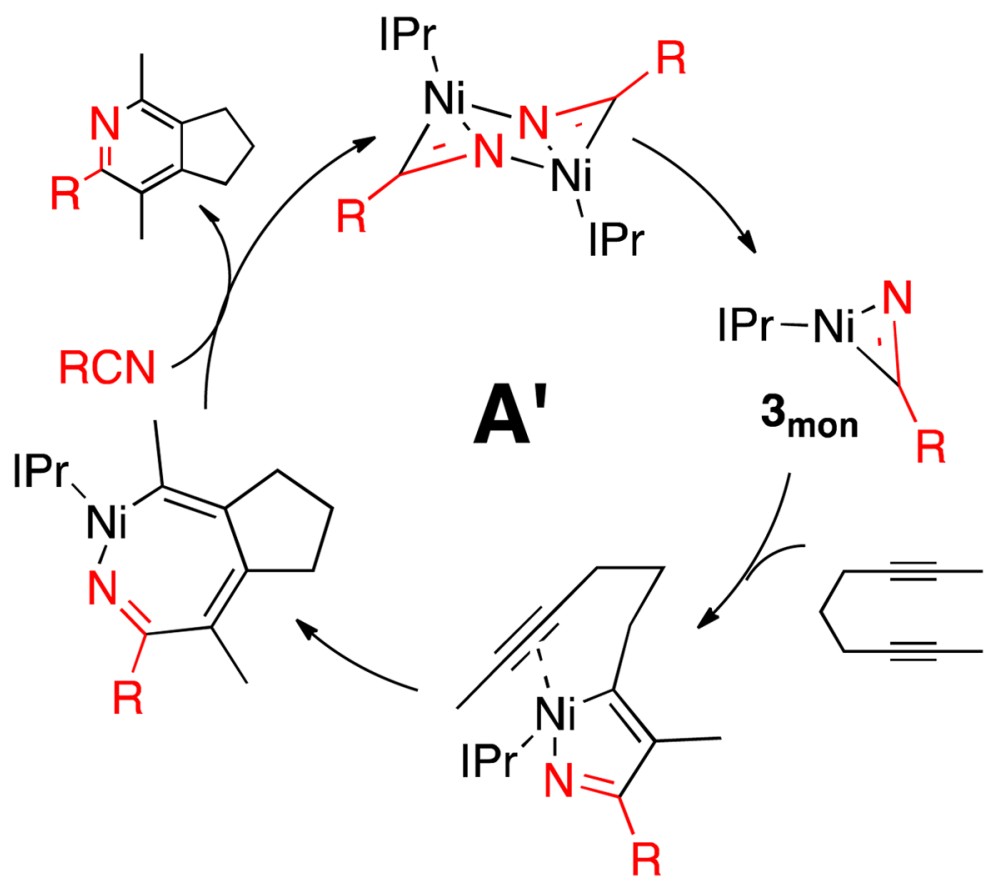

Scheme 4.

Modified Pathway A' 


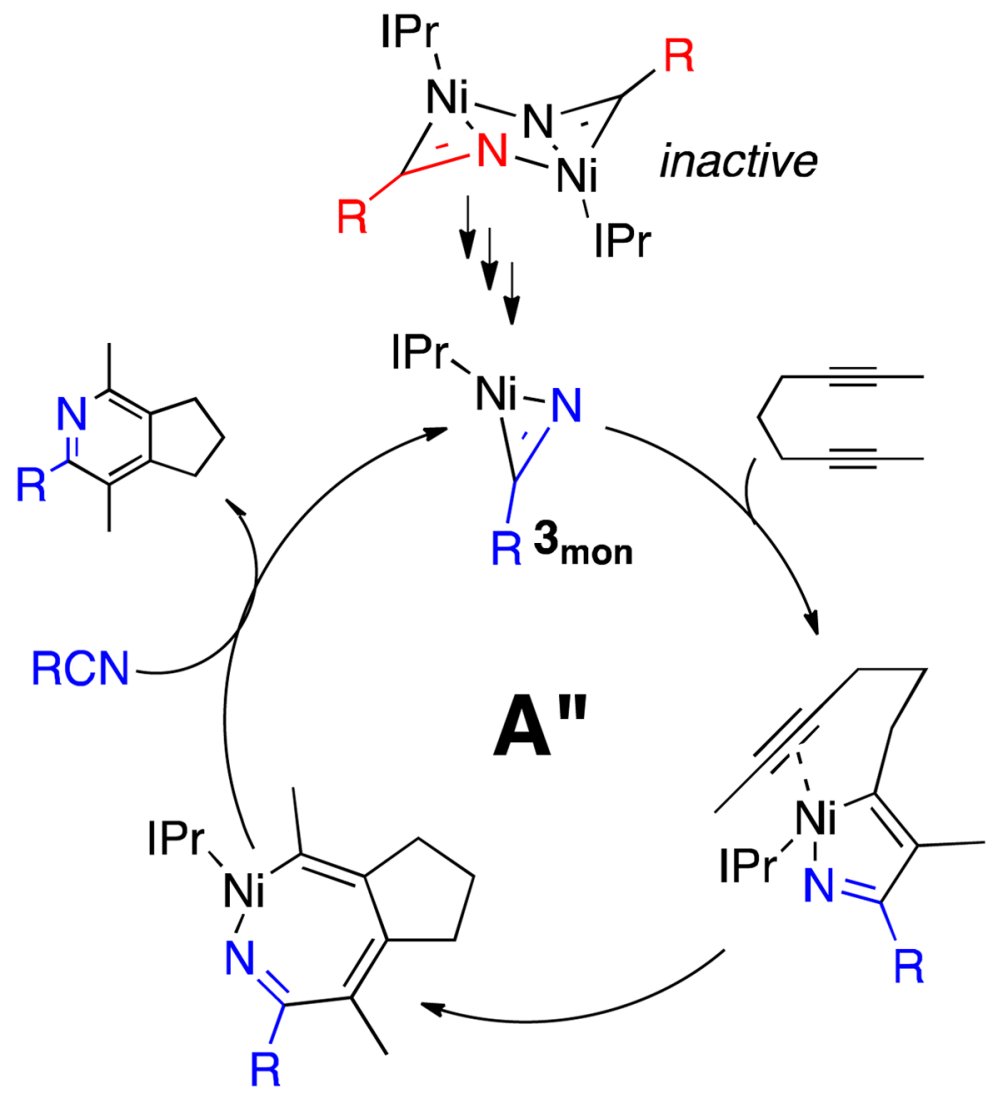

Scheme 5.

Modified Pathway A" 
<smiles>CC#CCCCC#CC</smiles>

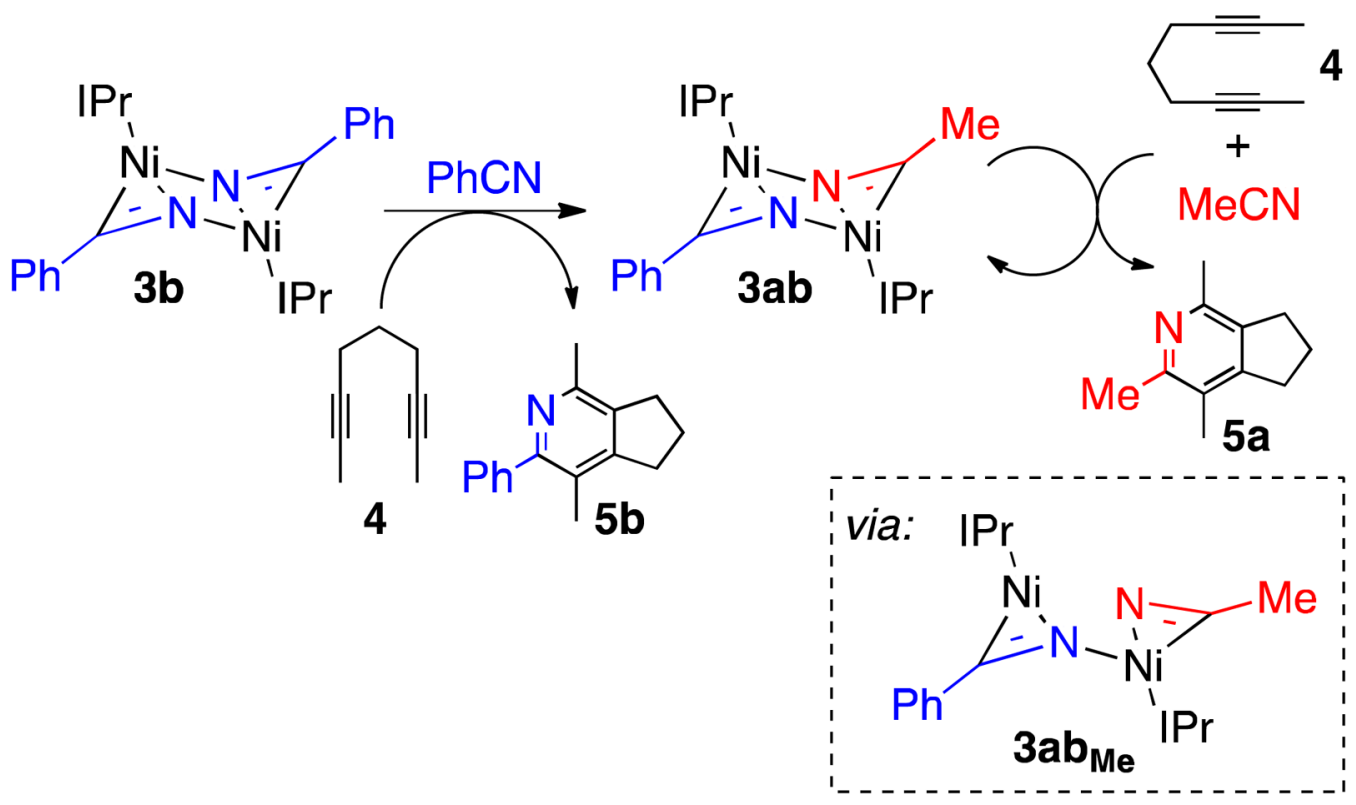

Scheme 6.

Contradictory reactivities of 3ab required by Pathway D to account for observed product ratios 


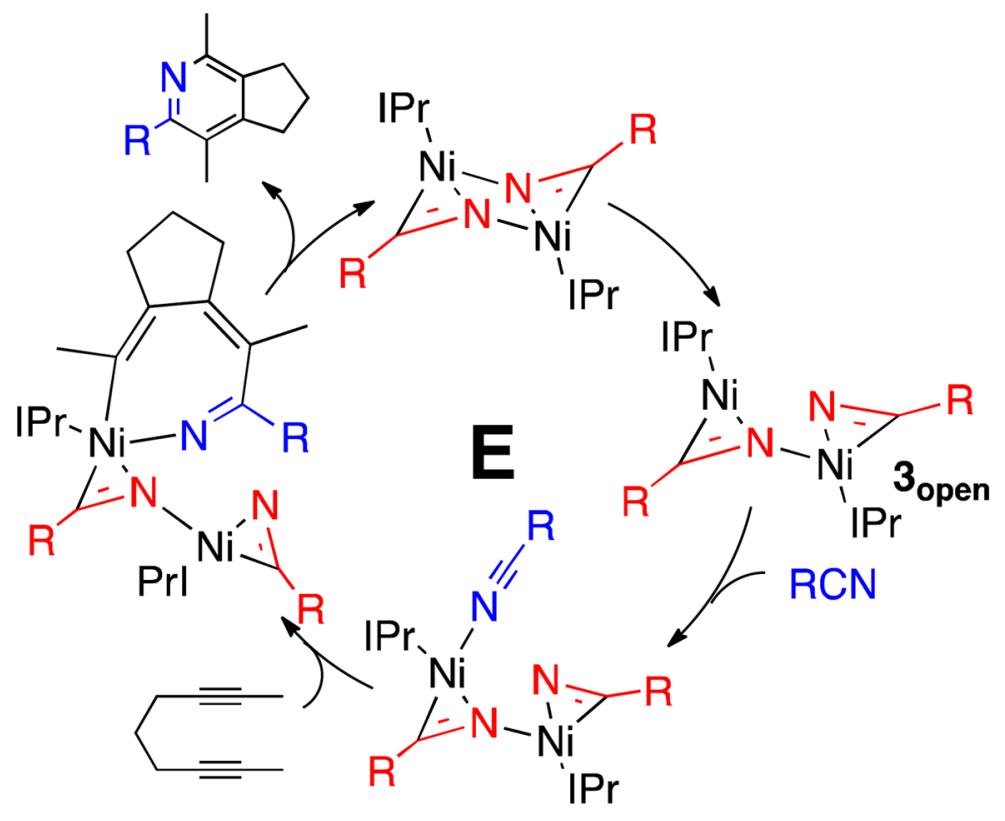

Scheme 7.

Proposed Mechanism of $[\mathrm{Ni}(\mathrm{IPr}) \mathrm{RCN}]_{2}$-Catalyzed Cycloaddition 
Table 1

Pyridine yields from stoichiometric cycloaddition reactions ${ }^{a}$

\begin{tabular}{clcc}
\hline entry & $\mathbf{R}$ & yield of $\mathbf{5}($ no added $\mathbf{R C N})$ & yield of $\mathbf{5}(\mathbf{w} / \mathbf{1}$ equiv RCN added) \\
\hline 1 & $\mathbf{5 a}, \mathrm{R}=\mathrm{Me}$ & $30 \%$ & $64 \%$ \\
2 & $\mathbf{5 b}, \mathrm{R}=\mathrm{Ph}$ & $34 \%$ & $91 \%$ \\
3 & $\mathbf{5 c}, \mathrm{R}=4-\mathrm{CF}_{3}-\mathrm{C}_{6} \mathrm{H}_{4}$ & $35 \%$ & $96 \%$ \\
4 & $\mathbf{5 d}, \mathrm{R}=4-\mathrm{MeO}-\mathrm{C}_{6} \mathrm{H}_{4}$ & $31 \%$ & $63 \%$ \\
\hline
\end{tabular}

${ }^{a}$ Dimer 3 (1 equiv), diyne 4 (1 equiv), w/ and w/out nitrile, $\mathrm{C}_{6} \mathrm{D}_{6}, 23^{\circ} \mathrm{C}$.

$b_{\text {Yields determined by }}{ }^{1}$ H NMR spectroscopy. 
Table 2

Pyridine yields and product ratios from stoichiometric cross-cycloaddition reactions $s^{a, b}$

\begin{tabular}{|c|c|c|c|c|}
\hline entry & dimer 3 & $\mathrm{R}_{2} \mathrm{CN}$ (equiv) & yield of $5\left(R_{1}: R_{2}\right)$ & post-reaction dimer species \\
\hline 1 & $\mathbf{3 a}$ & $\mathrm{PhCN}(1)$ & $84 \%(1: 27)$ & $\mathbf{3 a}$ \\
\hline 2 & $\mathbf{3 b}$ & $\mathrm{MeCN}(1)$ & $74 \%(1: 1.6)$ & $\mathbf{3 b}$ \\
\hline 3 & $\mathbf{3 b}$ & $\mathrm{MeCN}(10)$ & $67 \%(1: 2.9)$ & $\mathbf{3 b} / \mathbf{3} \mathbf{a}^{c}$ \\
\hline 4 & $\mathbf{3 b}$ & $4-\mathrm{CF}_{3}-\mathrm{C}_{6} \mathrm{H}_{4}(1)$ & $93 \%(1: 4.5)$ & $\mathbf{3 b} / \mathbf{3} \mathbf{d}^{c}$ \\
\hline 5 & $\mathbf{3 b}$ & $4-\mathrm{MeO}-\mathrm{C}_{6} \mathrm{H}_{4}(1)$ & $95 \%(1: 4)$ & $\mathbf{3 b}$ \\
\hline 6 & $3 c$ & $\mathrm{MeCN}(1)$ & $63 \%(1: 1.4)$ & $3 c^{c}$ \\
\hline 7 & $3 c$ & $\mathrm{MeCN}(10)$ & $91 \%(1: 1.9)$ & $3 \mathbf{c}^{c, d}$ \\
\hline 8 & $3 \mathrm{c}$ & $\mathrm{PhCN}(1)$ & $96 \%(1: 4.3)$ & $3 c^{c}$ \\
\hline 9 & 3d & $\operatorname{MeCN}(1)$ & $69 \%(1: 2.1)$ & 3d \\
\hline 10 & 3d & $\mathrm{PhCN}$ (1) & $99 \%(1: 11)$ & 3d \\
\hline
\end{tabular}

${ }^{a}$ Dimer 3 ( 1 equiv), diyne 4 (1 equiv), nitrile (1 equiv), $\mathrm{C}_{6} \mathrm{D} 6,23{ }^{\circ} \mathrm{C}$.

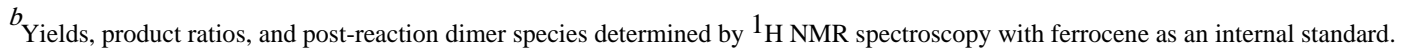

$c_{\text {Traces of unknown Ni species were detected. }}$

$d_{\text {Complex mixture of Ni products were formed. }}$ 